\title{
1 Removal of oxyfluorfen from spiked soils using electrokinetic
}

\section{2 soil flushing with the surrounding arrangements of electrodes}

3 C. Risco ${ }^{1}$, H. Rubí-Juárez ${ }^{2}$, S. Rodrigo ${ }^{3}$, R. López Vizcaíno ${ }^{3}$, C. Saez ${ }^{1}$, P. Cañizares ${ }^{1}$, C.

4

5

6

7

8

Barrera-Díaz $^{2}$, V. Navarro ${ }^{4}$, M.A. Rodrigo ${ }^{1, *}$

${ }^{1}$ Department of Chemical Engineering, Instituto de Tecnologías Química y Medioambiental, University of Castilla-La Mancha, Campus Universitario s/n, 13071 Ciudad Real, Spain

${ }^{2}$ Facultad de Química, Universidad Autónoma del Estado de México, Paseo Colón intersección Paseo Tollocan S/N, C.P. 50120, Toluca, Estado de México, Mexico

${ }^{3}$ Department of Chemical Engineering, Facultad de Ciencias y Tecnologías Químicas, University of Castilla-La Mancha, Campus Universitario s/n, 13071 Ciudad Real, Spain ${ }^{4}$ Geoenvironmental Group, Civil Engineering School, University of Castilla-La Mancha, Avda. Camilo José Cela s/n, 13071 Ciudad Real, Spain

\section{Abstract}

This work reports the results of a study in which the remediation of soil that undergoes an accidental discharge of oxyfluorfen is carried out by using electrokinetic soil flushing (EKSF). Two different electrode configurations were tested, consisting of several electrodes surrounding an electrode of different polarity (so-called 1A6C, one anode surrounded by six cathodes, and 1C6A, one cathode surrounded by six cathodes). A pilot plant scale was used (with a soil volume of $175 \mathrm{dm}^{3}$ ) to perform the studies. During the tests, different parameters were measured daily (flowrates, $\mathrm{pH}$, electrical conductivity and herbicide concentration in different sampling positions). Furthermore, at the end of the test, a complete post-mortem analysis was carried out to obtain a 3-D map of the pollution, $\mathrm{pH}$ and electrical conductivity in the soil. The results demonstrate that electrode 
1 arrangement is a key factor for effective pollutant removal. In fact, the $1 \mathrm{~A} 6 \mathrm{C}$

2 configuration improves the removal rate by $41.3 \%$ versus the $27.0 \%$ obtained by the

3 1C6A configuration after a period of 35 days. Finally, a bench mark comparison of this

4 study of soil remediation polluted with 2,4-D allows for significant conclusions about the

5 scale-up and full-scale application of this technology.

6

$7 \quad$ Keywords

8 Oxyfluorfen, herbicide, electroremediation, surrounded electrodes, pilot plant

9

\section{Highlights}

- The electrode arrangement has a crucial influence on the results attained by EKSF

- The 1C6A configuration is more efficient and overcomes $1 \mathrm{~A} 6 \mathrm{C}$ by $53 \%$

- Dragging of herbicide by EOF and volatilization are efficient mechanisms in EKSF

- The $\mathrm{pH}$ in soil is well controlled by both the $1 \mathrm{C} 6 \mathrm{~A}$ and the $1 \mathrm{~A} 6 \mathrm{C}$ configurations

- The results of EKSF are not easily predictable because of the large number of parameters involved

* To whom all correspondence should be addressed: manuel.rodrigo@uclm.es 
3 Electrokinetic soil remediation is a very efficient technology for the removal of hazardous

4 ions from soil. However, at the moment, there are few studies that focus on organic soil

5 removal (Alcantara et al., 2010; Alcantara et al., 2012; Alshawabkeh et al., 1999a;

6 Cameselle and Reddy, 2013; Hahladakis et al., 2013; Hahladakis et al., 2014; Lima et al.,

7 2011; Lu and Yuang, 2009; Pazos et al., 2010; Reddy et al., 2011; Reddy et al., 2009;

8 Ribeiro et al., 2011; Ribeiro et al., 2005; Weng, 2009).

9 For an optimal performance, the electrokinetic soil flushing (EKSF) process relies on a satisfactory electrode arrangement (Jeon et al., 2015; Kim et al., 2012; Kim et al., 2015; Rodrigo et al., 2014a). Until now, the most widely studied arrangement is facing two linear rows of electrodes with different polarities (Risco et al., 2016a). The advantages of this configuration are related to the expected better electric current distribution lines, which are also expected to produce a well-distributed pattern of electrokinetic flows within the soil and, hence, a very efficient drainage of pollution.

However, this is not the only possibility of placing electrodes in soil (Almeira et al., 2009; Alshawabkeh et al., 1999a; Alshawabkeh et al., 1999b; Peng et al., 2013), and configurations in which various electrodes surround a central electrode of the opposite polarity have also been tested, showing very interesting performances. At this point, it is important to remark that the recent literature indicates that the position of the electrodes sited in the soil is a key parameter in the remediation efficiency because it determines the direction and magnitude of the electrokinetic processes, and consequently, it influences the transport of pollutants. For this reason, different research works during the last few years have focused on the evaluation of the electrode configuration (Adams et al., 1997; Almeira et al., 2009; Jeon et al., 2015; Kim et al., 2012). The results obtained in these 
studies indicate that the most effective electrode configuration (from a pollutant transport viewpoint) is a hexagonal configuration, that is, a ring of anodes with a central cathode, or vice versa, depending on the polarity of the pollutant. The number of electrodes and the electrode spacing used are directly related with the mass of the treated soil.

In a previous report of this group (Risco et al., 2016c), two of these configurations were applied in a soil that underwent a simulated discharge of herbicide 2,4-D. The study was conducted in a mock-up with a suitable size to fully understand the effect on the remediation of the different flows induced by the electric field. The results indicate that the pollutant was removed by electromigration, electroosmostic fluxes and volatilization. In this work, we aim to expand our technology knowledge using a very different model of pesticide, the oxyfluorfen. This herbicide belongs to the diphenyl ether chemical group and has low water solubility $\left(0.116 \mathrm{mg} / \mathrm{L}\right.$ at $\left.20^{\circ} \mathrm{C}\right)$, low vapor pressure $(0.026 \mathrm{mPa}$ at 25 $\left.{ }^{\circ} \mathrm{C}\right)$, high Koc $(\log \mathrm{Koc}=3.46-4.13)$, and high Kow $(\log$ Kow $=4.86)$. As oxyfluorfen is not metabolized in plants and is subjected to very little translocation, phototransformation is suggested as the only possible abiotic degradation process. Microbial degradation is not a major factor to be accounted for in this herbicide. The half-life in soil approximately ranges from 30 to 56 days, and the organic matter content of the soil seems to influence the oxyfluorfen persistence and activity (Sondhia, 2010; Sondhia and Dixit, 2010). Finally, regarding its transport properties, it has been observed (Mantzos et al., 2014) that oxyfluorfen hardly moves into silty clay soil and exhibits low run-off potential. In this work, the effect of the electrode arrangements in EKSF is studied in a soil mockup, and then, the remediation technology is applied for more than a month. The results are compared with a reference experiment in which the discharge is simulated but no treatment is applied. The results are also discussed with respect to the results obtained in 
our previous works, which focused on the removal of 2,4-D (Risco et al., 2016a; Risco et al., 2016c; Risco et al., 2015), a pollutant with an expected higher water solubility and volatility and, hence, with very different expected results in terms of the efficiency of the EKSF treatment. For this reason, the comparison carried out in this work will provide relevant conclusions on EKSF technology.

\section{Materials and Methods.}

Soil properties and flushing solutions. Field soil from Toledo (Spain) was used in this study. This soil is characterized by its inertness, low hydraulic conductivity and lack of organic content. The mineralogical composition and the parameters used to classify this soil by the Unified Soil Classification System (USCS) are listed elsewhere (LopezVizcaino et al., 2014a; Lopez-Vizcaino et al., 2014b)(Risco et al., 2016b). In addition, particle size distribution of the soil was measured by a laser diffraction particle size analyser (model LS 13320, Beckman Coulter) with an aqueous module. This analysis indicates that the soil are composed on these fractions: $4.9 \%$ clay, $68.2 \%$ silt and $26.9 \%$ sand, therefore it can be classified as a silty loam according with the texture classification of the United States Department of Agriculture (USDA).

Oxyfluorfen was used as the model of non-polar and hydrophobic herbicide. The commercial herbicide used was Fluoxil 24 EC (CHEMINOVA AGRO, S.A., Madrid, Spain) composed on 24\% (v/v) Oxyfluorfen dissolved in aqueous solution by the emulsifier action of Calcium Dodecylbenzenesulfonate (surfactant included in a commercial solution).

Experimental setup. The electrokinetic experiments were conducted in two electrokinetic remediation plants, each of them consisting of an electrokinetic reactor, a power source and tanks of electrolyte. A layout of the two setups used is shown in Figure 
1 1. The reactors were methacrylate prisms with a soil capacity of $175 \times 10^{3} \mathrm{~cm}^{3}$ (LWH:

$270 \times 50 \times 50 \mathrm{~cm}^{3}$ ). The electrodes (used for both the anodes and the cathodes) were graphite

3 rods with dimensions $1 \times 1 \times 10 \mathrm{~cm}^{3}$, positioned in semipermeable electrolyte wells, using

4 the electrode configuration shown in Figure 1, in which six electrodes surround a central

5 electrode of different polarity (configuration 1A6C: anode surrounded by 6 cathodes;

6 configuration 1C6A: cathode surrounded by 6 anodes). The cathodic wells are connected

7 to $100 \mathrm{~cm}^{3}$ sewers to accumulate the fluid transported through the soil and facilitate

8 sampling. The reactor is designed to separate and collect the fluids through an outlet

9 situated on the side wall of the reactor. To monitor the flux of water and the temperature

10 evolution during the experiment, tensiometers, thermocouples and rhizon samplers (or

11 "rhizons") were inserted into the soil. Figure 1 shows the instrumentation of the plant.

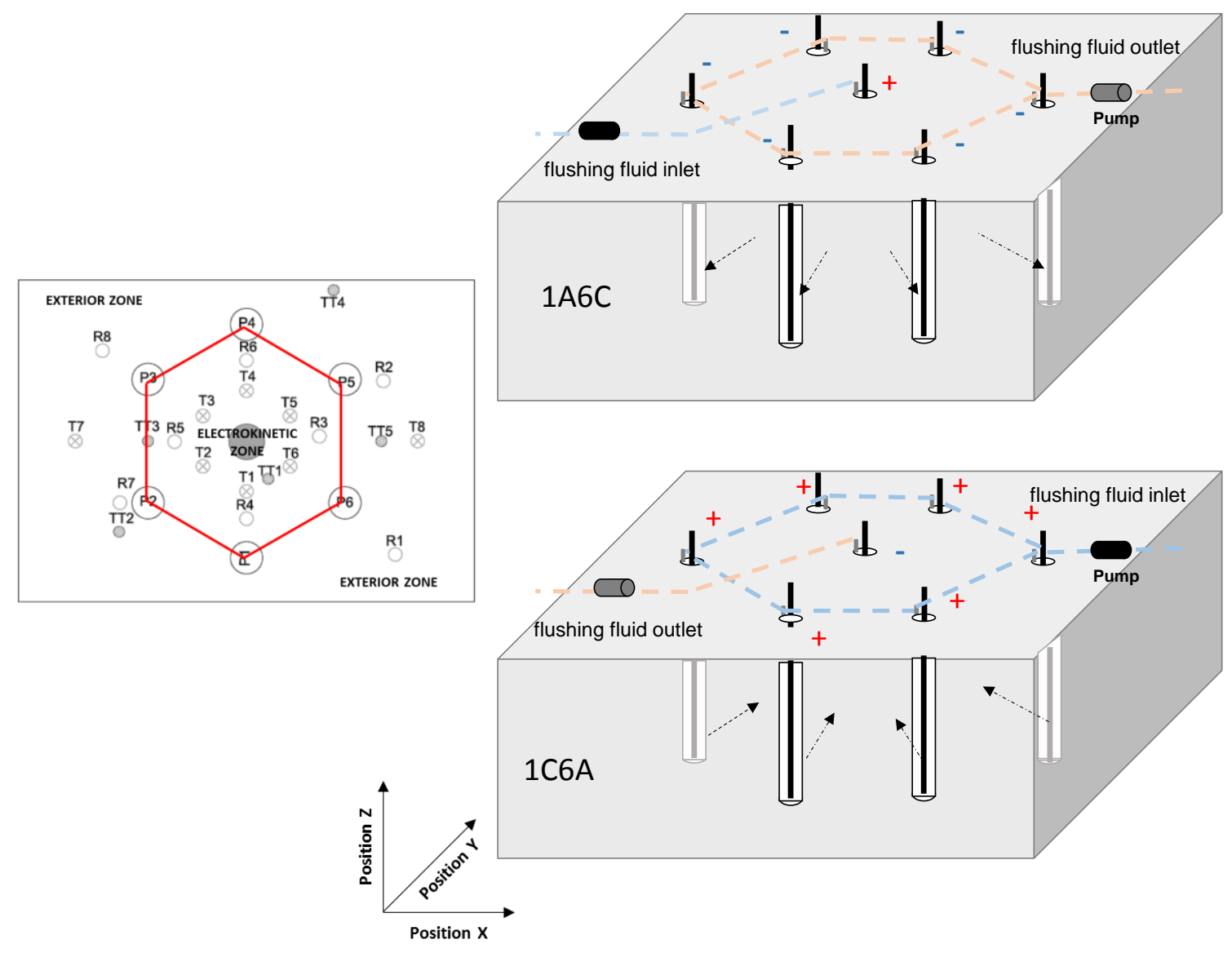


Figure 1. Diagram of the electrokinetic remediation plant and configuration of the instrumentation.

4 Experimental procedure. The process of the preparation of the soil is important because

5 of the complexity of natural soil. The process was divided into four different stages:

$6 \quad-\quad$ installation of three layers of gravel with different particle sizes for mechanical information obtained in the literature(Rodrigo et al., 2014b).

Analyses. To characterize the EKSF treatment efficiency, the electrical current, temperature, $\mathrm{pH}$, soil water content and oxyfluorfen concentration in electrolyte wells 
1 were monitored daily, and at the end of the experiments, an in-depth sectioned analysis

2 of the complete soil section was conducted. The $\mathrm{pH}$ and electrical conductivity were

3 measured with an InoLab WTW pH meter and a GLP 31 Crison conductivimeter,

4 respectively. The electric current was measured with a KEITHLEY 2000 Digital

5 Multimeter. The temperature was measured with PT-100 thermocouples. To quantify the

6 amount of oxyfluorfen in the liquid samples, an L-L extraction process in Eppendorf tubes

$7 \quad\left(15 \mathrm{~cm}^{3}\right)$ was used, using ethyl acetate as the solvent (ratio polluted soil/solvent $=0.7$

8 w/w). Both phases were vigorously stirred in a vortex mixer (VV3 VWR multi-tube) for

92 minutes, and the organic phase was separated from water. The organic phase was then

10 placed into tubes to be stripped with $\mathrm{N}_{2}$ gas. A volume of $1.5 \mathrm{~cm}^{3}$ of acetonitrile is then

11 added and stirred for 3 minutes before being injected into the High Pressure Liquid

12 Chromatography (HPLC). To quantify the amount of oxyfluorfen in the soil, an L-S extraction process was used. The L-S extraction process was carried out in Eppendorf tubes $\left(15 \mathrm{~cm}^{3}\right.$ ) using ethyl acetate as solvent (ratio polluted soil/solvent $=0.4 \mathrm{w} / \mathrm{w}$ ). Both phases were vigorously stirred in a vortex mixer (VV3 VWR multi-tube), and the subsequent phase separation was accelerated by the use of a centrifuge rotor angular (CENCOM II P-elite) for 20 minutes and $4000 \mathrm{rpm}$. Then, liquid was stripped with $\mathrm{N}_{2}$ gas, and acetonitrile was added before being injected into the HPLC. The HPLC used was Agilent 1100 (Agilent Technologies, Palo Alto, California, EEUU) with an UV detector with Acetonitrile (70\%)/water (30\%) as the carrying fluid at a flowrate of $0.25 \mathrm{~cm}^{3} \mathrm{~min}^{-}$

$211^{1}$ using a column Gemini $5 \mu \mathrm{C} 18$ 110 (Phenomenex, Ref. 00F-4435-YYO) with 22 dimensions of $150 \times 3.0 \mathrm{~mm}$ and a wavelength of $220 \mathrm{~nm}$.

\section{Results and Discussion}


1 Figure 2 shows the changes in the current intensity and in the volume of water added in

2 the anode wells during the two tests carried out to evaluate the performance of the two

3 ESKF strategies based on the placement of electrodes of the same polarity surrounding a

4 central electrode with a different polarity.

5

6

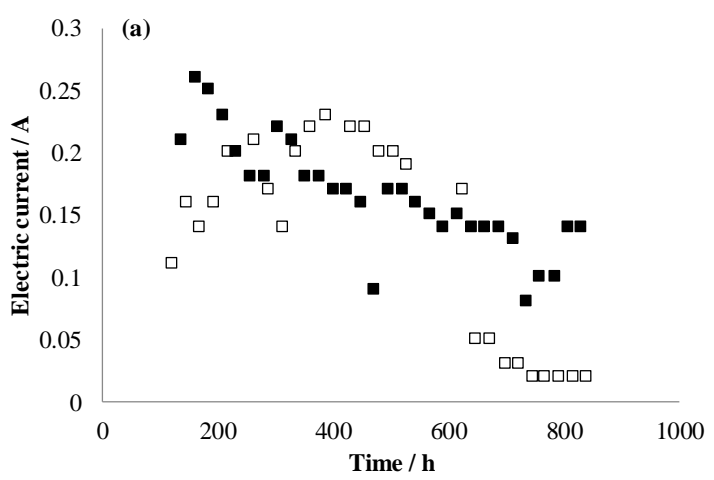

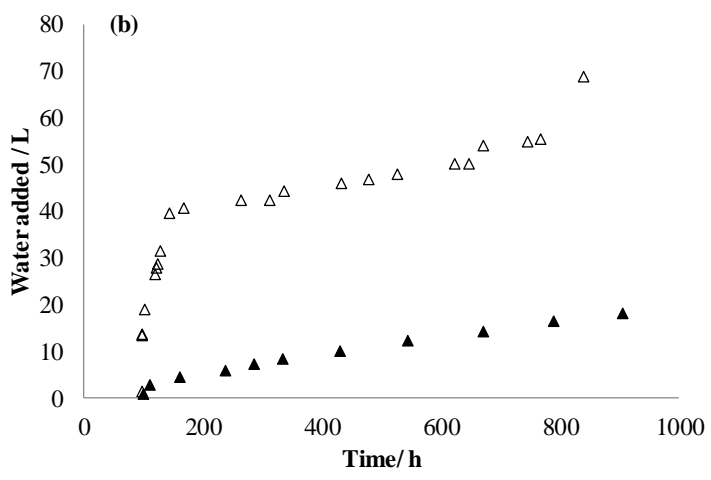

7 Figure 2. Changes in the (a) electric current and (b) volume of water added in the anode

8 wells over the two EKSF tests. Unfilled markers 1C6A, filled markers 1A6C.

9

As it can be observed, there are important similarities and differences between the performance of both configurations. For both arrangements of electrodes, the current intensity increases rapidly in the mockups up to a maximum value, reached at 200 hours in the case of the $1 \mathrm{~A} 6 \mathrm{C}$ and slightly later (at 400 hours) in the case of the 1C6A configuration. In both cases, the maximum intensity attained is slightly over $0.20 \mathrm{~A}$. Then, the decrease in the intensity obtained in the $1 \mathrm{C} 6 \mathrm{~A}$ is more abrupt than in the $1 \mathrm{~A} 6 \mathrm{C}$ configuration. In comparing the amounts of water demanded in the anodic wells to maintain a constant level, it can be seen that the 1C6A demands more than three times the volume of water required by the $1 \mathrm{~A} 6 \mathrm{C}$ configuration to keep the level of water in the anode wells (68.7 vs. $\left.18.0 \mathrm{dm}^{3}\right)$. In fact, this is a key point in the comparison of both configurations. In the 1A6C configuration, there is no effective electro-osmotic flow, and almost no water reaches the cathode wells, as observed in Figure 3, which shows the 
1 electro-osmotic flow calculated with the volume of water collected at the cathodes in both

2 configurations. When comparing this value with the value added in the anode wells, the

3 significance of the water evaporation process can be noted. It can also be noted that the

4 electro-osmotic flow is strongly related with the profile of the intensity of the electric

5 current. In a previous work focused on the treatment of soil spiked with 2,4-D in the same

6 experimental device (Risco et al., 2016c), a similar conclusion was drawn. This result

7 means that controlling water flows in a strategy with several cathode wells, like the $1 \mathrm{~A} 6 \mathrm{C}$

8 strategy, should be improved if an efficient technology is to be obtained. At this point, it

9 is important to take into account that, to try to avoid the failure of the EK processes

10 because of the lack of electrolyte continuity, water was added each day at the cathode

11 wells. The surplus water was taken at the end of each day (before being replaced with a new volume of water), as will be discussed afterwards.

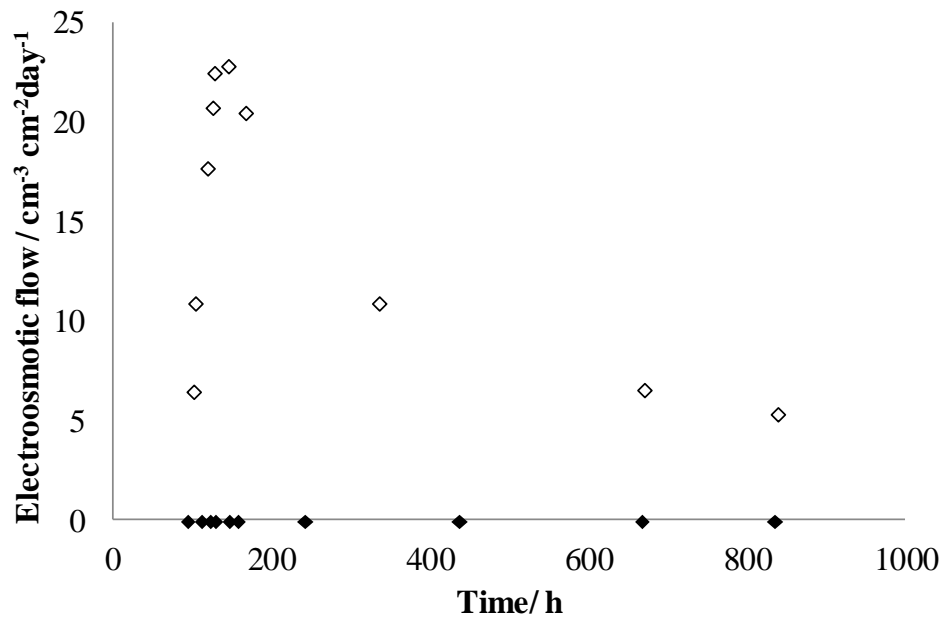

Figure 3. Electroosmotic flow collected at the cathodes in the two EKSF tests. Unfilled markers 1C6A, filled markers 1A6C.

This lack of water in the cathode wells does not correspond to the complete dryness of the soil but just the opposite. In fact, it only means that water does not get into the well. 
1 Figure 4 shows a 2-D plot of the water content of the soil after the treatment tests (average

2 values of the samples in the same $x y$ position at different $\mathrm{z}$ coordinates). It can be

3 observed that there are no great differences between the water contents in the soil. The

4 water content in the soil that undergoes the 1A6C strategy is higher than that shown by

5 the 1C6A strategy. This soil water content is also greater than that obtained in the

6 reference experiment after the same experimental time (9.9\%). Hence, what is not

7 promoted in the $1 \mathrm{~A} 6 \mathrm{C}$ strategy is the transport of water to the wells more than the drying

8 of the soil. This can be a problem related to the improper distribution of electric current

9 lines in this configuration to provide an adequate flow between the anode and each of the 10 cathodes.

(a)

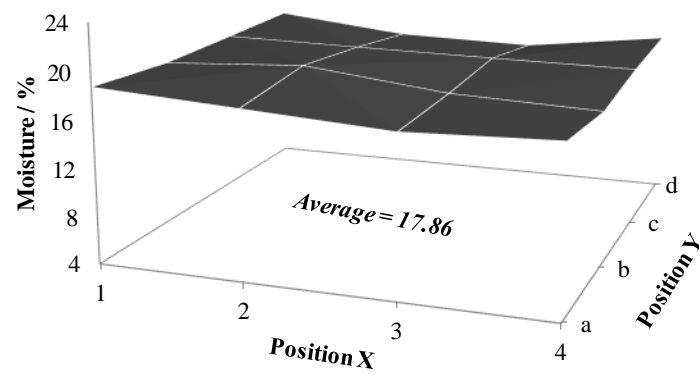

(b)

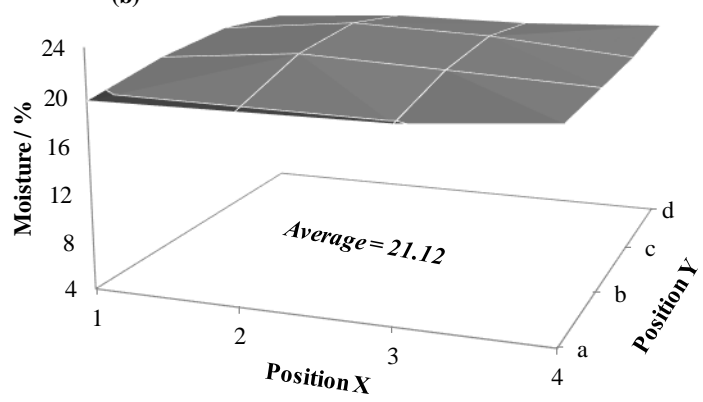

12

Figure 4. 2-D plot of the soil water content distribution after the two EKSF tests. (a) 1C6A and (b) $1 \mathrm{~A} 6 \mathrm{C}$.

One very important parameter in the EKSF processes is the $\mathrm{pH}$, which is also directly related to intensity of the electric current. The $\mathrm{pH}$ is known to change in a different fashion (Lopez-Vizcaino et al., 2011) in both the anode and the cathode, as shown in Figure 5. However, despite these huge changes in the $\mathrm{pH}$ inside the cathode and anodic wells, both configurations are very effective in the neutralization of the $\mathrm{pH}$ fronts, and there are no extreme variations between the different zones of the soil, as shown in the 2-D maps 
1 obtained after the postmortem analysis of the mockups, once the tests were over. The

2 changes are higher in the case of the 1A6C configuration, perhaps because of the lower

3 flow of water, which prevents neutralization. However, in both cases, the results are very

4 similar, and there are no large changes, such those obtained in the EKSF processes with

5 linear rows of anodes facing linear rows of cathodes (Lopez-Vizcaino et al., 2014a;

6 Lopez-Vizcaino et al., 2014b; Risco et al., 2016a).

(a)

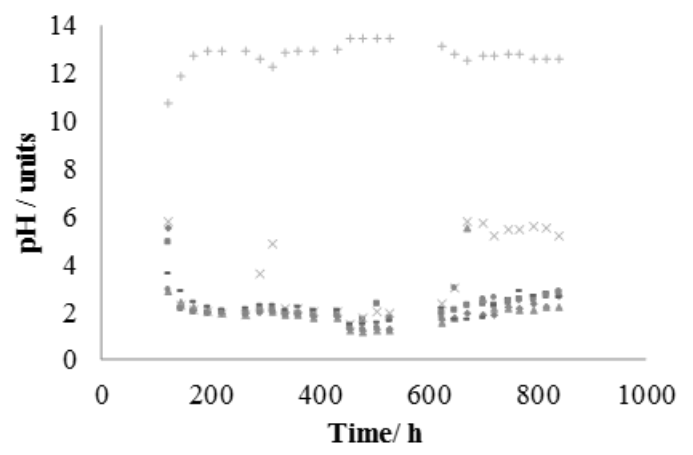

(b)

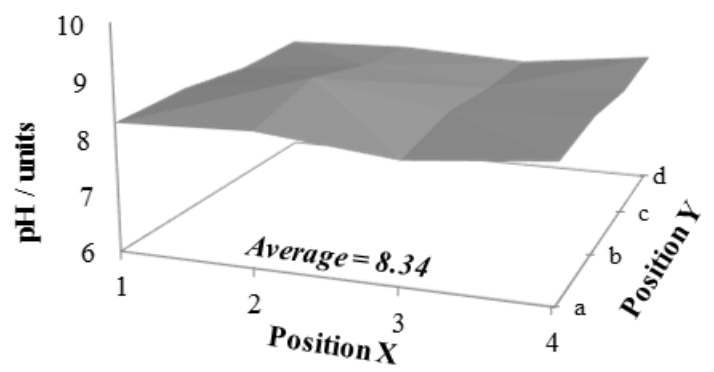

(a')

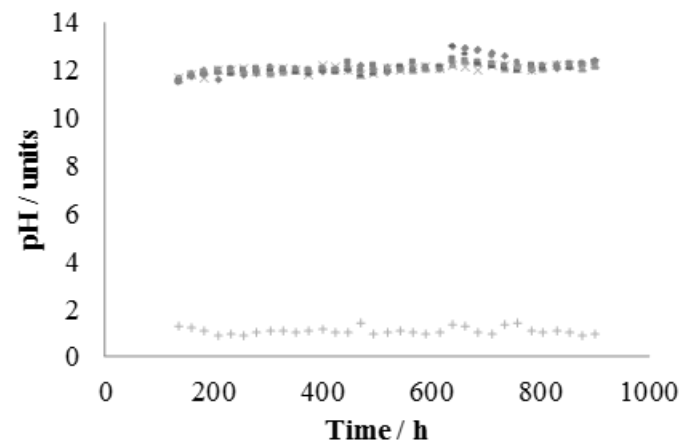

(b')

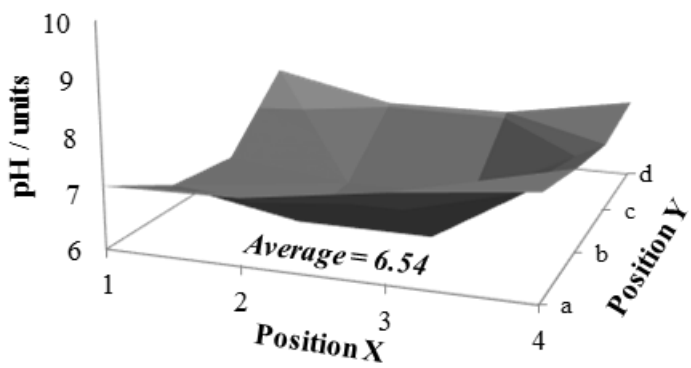

7

8 Figure 5. $\mathrm{pH}$ changes during the electrokinetic remediation test measured in the 9 electrolyte wells $(\bullet \mathrm{P} 1, \boldsymbol{\mathrm { P }} 2, \boldsymbol{\Delta} \mathrm{P} 3, \mathrm{x}$ P4, $-\mathrm{P} 5, \bullet \mathrm{P} 6,+\mathrm{P} 7)$ in both tests: (a) 1C6A and

Figure 6 compares, by using 2-D maps, the concentration of herbicide after the two EKSF processes with different configurations of the surrounding electrodes with the concentration remaining in the soil after the same experimental time in the reference test 
1 without any EKSF remediation process after this spill. This test can be considered a blank

2 experiment, and the differences between the two EKSF tests and the reference test allow

3 us to understand the processes that are directly caused by an electric field applied between

4 electrodes and to note the effect of processes not directly related to electrokinetics.
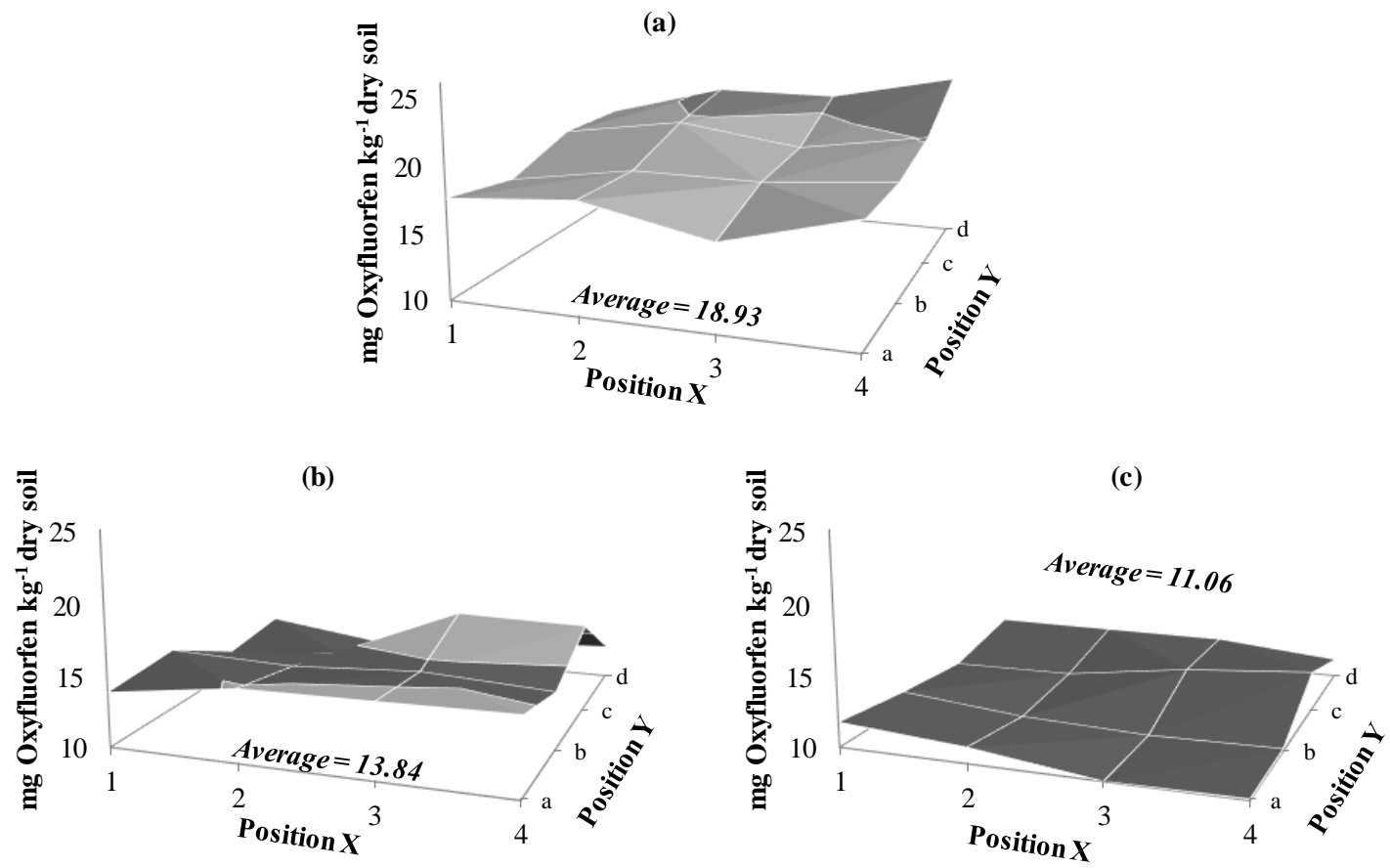

7

8 Figure 6. 2-D plots of the concentration of oxyfluorfen: (a) reference experiment; after

934 days of application of the EKSF: (b) 1C6A and (c) 1A6C.

The results obtained with both strategies are sound, and they indicate that herbicides are efficiently removed from the soils. The 1A6C strategy is slightly more efficient than the 1C6A configuration because of the lower remaining concentration in the soil after the test. Hence, the average concentration in the soil in the reference test decreases from the added $20.00 \mathrm{mg} \mathrm{kg}^{-1}$ (this is the concentration expected in case a uniform distribution is attained after the simulated accidental discharge) down to $18.93 \mathrm{mg} \mathrm{kg}^{-1}$, which means 
1 that, even in a soil without any treatment technology, the pesticide is partially removed.

2 Evaporation and photolysis can help to understand this decrease, according to the

3 literature (Alister et al., 2009; Das et al., 2003; Mantzos et al., 2014; Sondhia, 2010;

4 Sondhia and Dixit, 2010). In this point, it is worth to take in mind that in comparing the

5 vapor pressure of oxyfluorfen $\left(0.026 \mathrm{mPa}\right.$ at $\left.25^{\circ} \mathrm{C}\right)$ with other less volatile pesticide like

6 chlorsulfuron $\left(3 \times 10^{-6} \mathrm{mPa}\right.$ at $\left.25^{\circ} \mathrm{C}\right)$ evaporation of oxyfluorfen can be even 10000 times

7 higher. Biological oxidation or phytoremediation are ineffective with this herbicide. In

8 comparing the results obtained in the reference test with those shown in the two 2-D maps

9 of oxyfluorfen (after the EKSF processes), there is a clear effect on the removal caused

10 by the application of the electric field. Thus, there is a decrease in the average

11 concentration, down to 13.8 (1C6A) and 11.1 (1 A6C) $\mathrm{mg} \mathrm{kg}^{-1}$ after 35 days of treatment.

This result indicates an improvement of $27.0 \%$ and $41.3 \%$ with respect to the soil not undergoing EKSF, respectively. This observation indicates that the electric field applied in both configurations is clearly inducing removal mechanisms of the herbicides contained in the soils.

Data obtained from the rhizons (Figure 1) provide information about the evolution of the concentration over the tests. Unfortunately, the $1 \mathrm{~A} 6 \mathrm{C}$ configuration leads to a system in which no water can be collected at the electrode wells and rhizons, and hence, there is no possibility of measuring the herbicide on the line. Water was added each day in the cathode wells to avoid a lack of electrolyte continuity $(\mathrm{pH}$ of this water changes abruptly once added). The surplus water was taken at the end of each day (before being replaced with a new volume of water) and contained a high concentration of oxyfluorfen, and it is the value registered as taken in the cathode wells (dragged to the cathodes). In the case of the 1C6A strategy, Figure 7 shows that, according to the 2-D concentration plot, there are no relevant differences in the amount of herbicides obtained in each sampling point and 
1 that the herbicide extraction rate decreases with time at each sampling point. The first

2 observation can be easily related to the flat herbicide distribution pattern observed in the

3 2-D map. On the other hand, the latter observation may be explained because of the

4 decrease in the concentration of the herbicide in the soil during the tests.

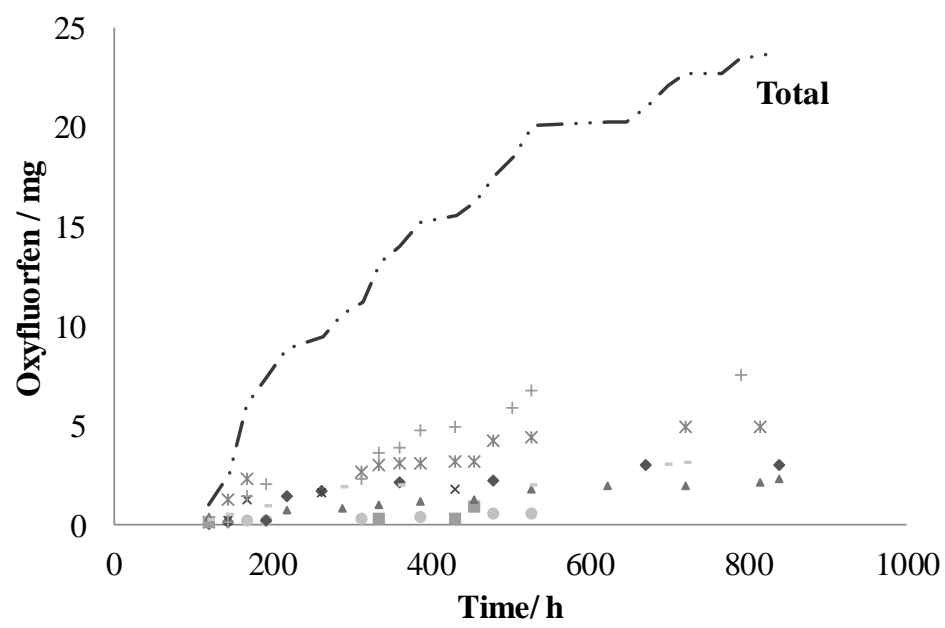

5

6 Figure 7. Herbicide collected at the different sampling points distributed across the soil

7 mock-up undergoing the 1C6A strategy. * R1, $\bullet \mathrm{R} 2, \bullet \mathrm{R} 3, \bullet \mathrm{R} 4, \boldsymbol{\Delta} \mathrm{R} 5, \mathrm{x}$ R6, + R7, $8 \quad \mathrm{R} 8$.

9

10 Coming back to the results of the postmortem analysis, a very interesting piece of 11 information can be obtained from the 3-D plot of both EKSF processes because this plot 12 provides information about potential differences in the concentration in the vertical axis 13 (z-axis according to Figure 1). Figure 8 shows a three-graph plot (each plot corresponding 14 to one layer of soil) for each of the electrode arrangements studied. There are no great differences between the plots, and the shape of the curve is maintained in the three horizontal layers monitored. Surprisingly, a higher concentration is measured in the top

17 layer, and this fact suggests that draining the herbicide (which consists of micelles) using 18 gravity is not a very favored process and leads to a concentration gradient. On the other 19 hand, the uniform distribution in each layer indicates the easiness of transport of this 
1 pesticide after an accidental discharge (at least within the time and size used in the

2 experimental tests), which contrasts what it is stated in other works about the mobility of

3 oxyfluorfen (Mantzos et al., 2014; Sondhia, 2010; Sondhia and Dixit, 2010). The mobility

4 in the horizontal plane seems to be contradictory to observation in the z-axis, but it may

5 be explained in terms of the current distribution lines generated during the EKSF process

6 because these vertical gradients are not observed in the blank tests (data not shown).

(a)
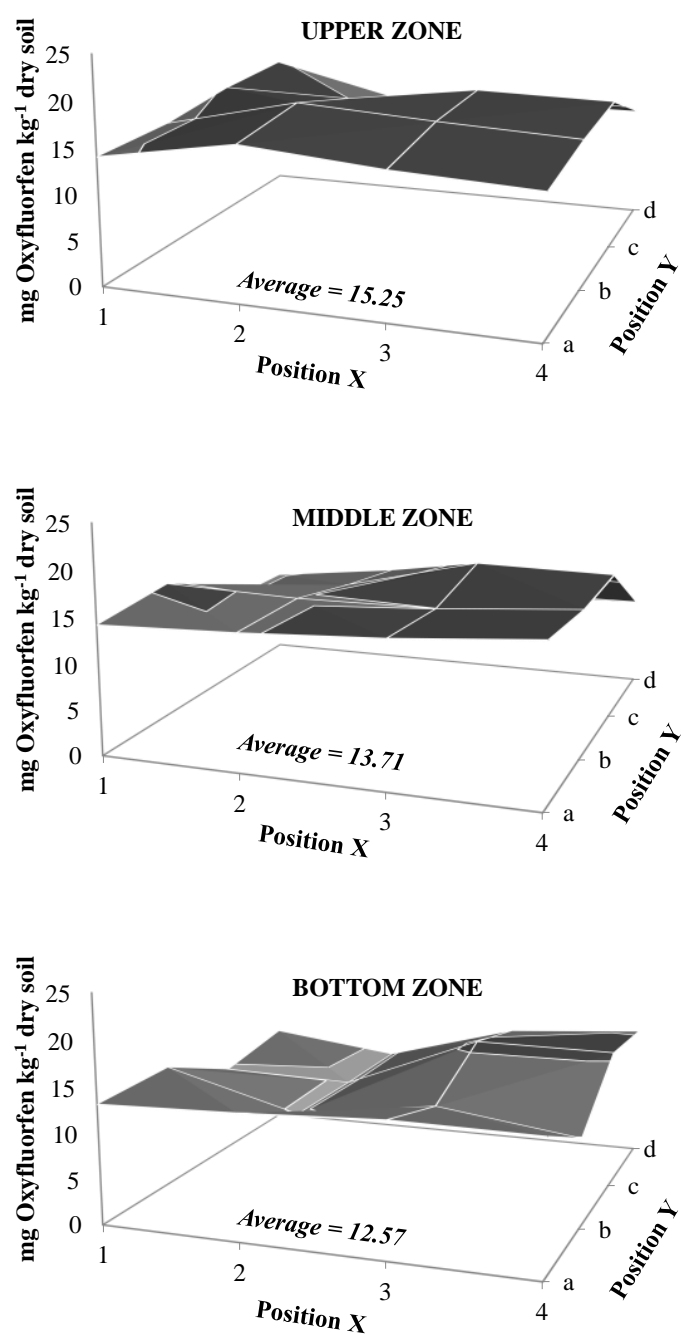

(b)
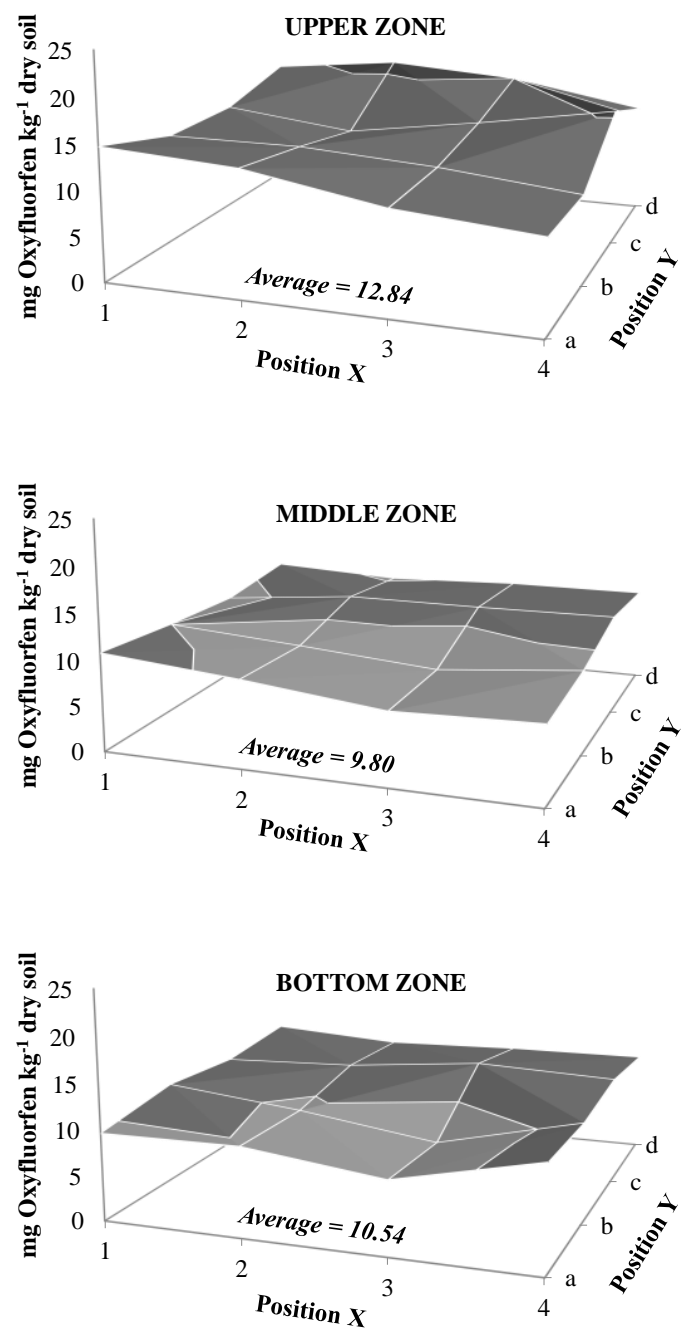

7

8 Figure 8. 3-D plots of the concentration of oxyfluorfen after the postmortem analysis.

9 (a) 1C6A and (b) 1A6C. 
1 Though the remediation tests started only 2 days after the discharge, the distribution of

2 pesticide in the soil is almost uniform, and the treatment does not affect the flat

3 distribution patterns of the herbicide but just the concentration remaining in the soil. This

4 observation was also noted in previous works of our research group with pesticides (Risco

5 et al., 2016a; Risco et al., 2015) and with other organics (Lopez-Vizcaino et al., 2014a;

6 Lopez-Vizcaino et al., 2014b). This result suggests the importance of reacting rapidly

7 once an incidental spill is detected in order to prevent the uncontrolled diffusion of

8 pollutants, which makes remediation more difficult and costly.

9 To conclude this discussion about the effects of the electrode arrangements on the 10 removal of oxyfluorfen by EKSF, it is important to check the mass balances of the 11 herbicide and water during the tests. The study presented in this work is a part of a more general study about the treatment of soils polluted with pesticides with different strategies, and the same electrode configurations were previously studied for the removal of pesticide 2,4-D from soils. Comparing the main results in order to check the influence of the nature of the pesticide on the development of EKSF process, can provide very valuable conclusions because of the very different transport characteristics of both pesticides. Thus, Figure 9 shows the distribution of the herbicide in the end of the experiment and compares it with the distribution of 2,4-D obtained after the same tests (in the same operation conditions) in order to obtain feedback about the influence of the characteristic of the pollutant molecule on the performance of the EKSF process (Risco et al., 2016c). The initial amount of pesticide spilled in the soil in both cases was 3000 mg. The adsorption of both pesticides in the soil was tested, checking that is nil. 
1

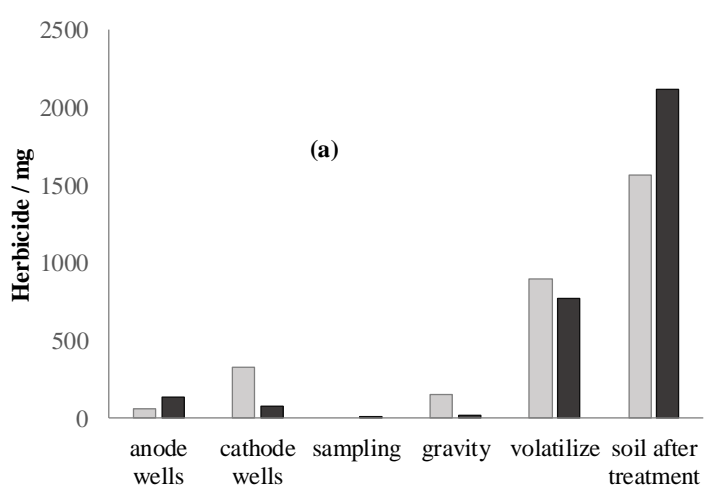

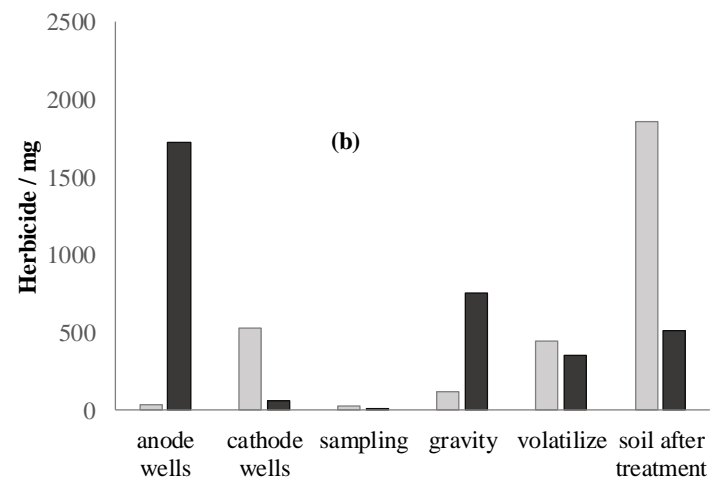

2 Figure 9. Distribution of oxyfluorfen (grey) and 2,4-D (black) after the application of

3 EKSF with the $1 \mathrm{~A} 6 \mathrm{C}$ (a) and 1C6A (b) strategies.

4 The results demonstrate that there is a huge influence of the characteristic of the pollutants

5 on the primary mechanisms affecting the transport of the pesticide in the soil.Transport

6 by electro-osmotic flow (collected in the cathode wells) is the primary EK mechanism for

7 the removal of oxyfluorfen, obtaining an $85.2 \%$ and $94.2 \%$ of the total removal of

8 oxyfluorfen by electrokinetic mechanisms with $1 \mathrm{~A} 6 \mathrm{C}$ and $1 \mathrm{C} 6 \mathrm{~A}$ configuration,

9 respectively. However, transport by electromigration (collected in the anode wells) is the primary EK mechanism for the removal of the ionic 2,4-D (64.2\% with 1A6C and $96.8 \%$ with 1C6A configuration, in respect of the total removal of 2,4-D by electrokinetic mechanisms). This transport mechanism is especially important in the 1C6A configuration, and it leads to a very efficient process for the removal of the anionic herbicide 2,4-D. The concentrations of oxyfluorfen collected at the anode wells can be explained in terms of the electrophoresis of the micelles of this pollutant; as expected, because of the steric limitations, this process is not as important as electromigration in

17 the case of 2,4-D. However, EK processes are not the only mechanisms to consider in order to understand the performance of the EKSF with the $1 \mathrm{~A} 6 \mathrm{C}$ or $1 \mathrm{C} 6 \mathrm{~A}$ configurations.

19 Volatilization plays a very important role in the results, and this volatilization is higher in the case of the 1A6C arrangement (around 28\%) than in the case of the 1C6A 
1 configuration (around 13\%). This result is observed in the remediation of both pesticides

2 studied (the oxyfluorfen and the 2,4-D). In addition, the volatilization of both pesticides

3 is comparable, and the volatilization of oxyfluorfen is slightly higher than that of 2,4-D.

4 This result is in agreement with the comparable values of the vapor pressure of both

5 compounds at room temperature (that is, $0.026 \mathrm{mPa}$ at $25^{\circ} \mathrm{C}$ for oxyfluorfen and 0.020

$6 \mathrm{mPa}$ at $25^{\circ} \mathrm{C}$ for $\left.2,4-\mathrm{D}\right)$.

7 The water mass balances are shown graphically in Figure 10. The evaporation flows are

8 similar in both systems, and they include the most important water flows measured in the

9 soil mockups. There are no big differences between the results obtained in the tests with

10 the two pesticides studied when the same arrangement is used. In comparing both

11 configurations, the evaporation in $1 \mathrm{~A} 6 \mathrm{C}$ is slightly greater than the evaporation of $1 \mathrm{C} 6 \mathrm{~A}$.

12 This result is in agreement with the observed higher volatilization of herbicide and 13 indicates that the capillary barrier is less effective in the case of the $1 \mathrm{~A} 6 \mathrm{C}$ configuration.

14 Gravity fluxes are less important than evaporation. In addition, the gravity fluxes 15 measured in the test with oxyfluorfen were slightly higher than those attained in the 16 remediation of the soil containing 2,4-D (Risco et al., 2016c). Regarding the volume of 17 water collected in the cathodes (associated with the electro-osmotic flux), in 1A6C, no water was collected (except for the volume collected during an unexpected event due to a valve failure registered during the 2,4-D test, which is not shown in the figure). On the other hand, the volume of water collected in the 1C6A configuration is very different in both tests, and it is much higher in the case of the remediation of soil polluted with oxyfluorfen. 
1

2 Figure 10. Distribution of water during the remediation test of soil polluted with

3

4

5 To know more about this point, the electrical conductivity and soil water content in the

6 four tests (two configurations with the two pesticides) are compared in Table 1.

7

8 Table 1. Average electrical conductivity and soil water content in different remediation 9 tests

\begin{tabular}{lcc}
\hline Configuration/ herbicide & $\begin{array}{c}\text { electrical } \\
\text { conductivity } \\
\mathrm{mS} \mathrm{cm}^{-1}\end{array}$ & $\begin{array}{c}\text { Soil water } \\
\text { content }\end{array}$ \\
\hline Configuration: 1C6A; herbicide: 2,4-D & 0.252 & 23.50 \\
Configuration: 1A6C; herbicide: 2,4-D & 0.222 & 28.84 \\
Configuration: 1C6A; herbicide: oxyfluorfen & 0.140 & 17.76 \\
Configuration: 1A6C; herbicide: oxyfluorfen & 0.123 & 21.06 \\
\hline
\end{tabular}
oxyfluorfen (grey) and 2,4-D (black) after the application of EKSF with the 1A6C (a) and 1C6A (b) strategies.
10

11 Although all the tests started with the same value of water content (11\%), the increase 12 experienced in the case of the $1 \mathrm{~A} 6 \mathrm{C}$ arrangement is higher than that in the case of the 13 1C6A configuration, and it is $48.5 \%$ higher in the case of $2,4-\mathrm{D}$ and $30.0 \%$ higher in the case of oxyfluorfen. The main difference is observed in the electrical conductivity, which
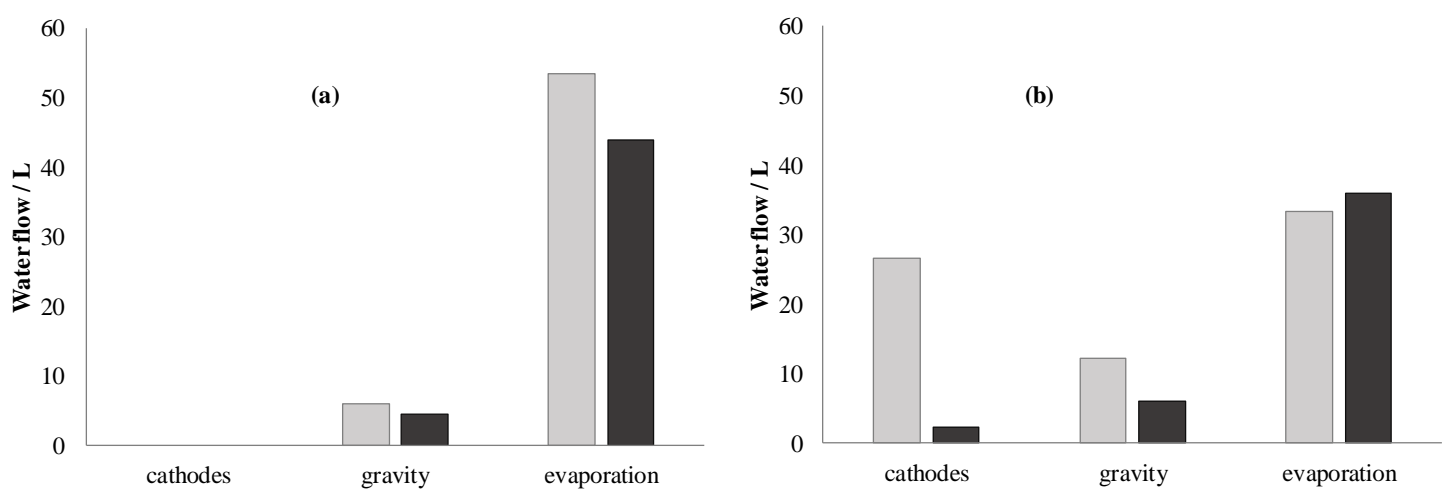
1 result can explain the lower EO flux because of the smaller width of the Debye layer

2 associated with the higher electrical conductivity of the system.

3 Hence, the results obtained with the application of the two configurations studied in this

4 work demonstrate that it is not easy to predict the performance of the system because of

5 the very large number of associated parameters. However, the technology seems to be

6 efficient, and high removals of oxyfluorfen (or 2,4-D) can be attained. Likewise, the

7 contribution of non-electrokinetic processes is quite relevant. In fact, the removal by

8 volatilization indicates that collecting this gaseous flow in order to attain a highly efficient

9 is mandatory and thus, complete treatment of the soil should be studied in the future.

\section{Conclusions}

From this work the following conclusions can be drawn:

- Oxyfluorfen can be successfully removed from soil using EKSF, with the arrangement of electrodes consisting of several electrodes surrounding one electrode of different polarity. It can attain a 27 or $41 \%$ improvement in the removal of oxyfluorfen (vs. natural volatilization) after 34 days of treatment using 1C6A and 1A6C configurations, respectively.

- Very different results are obtained between the 1C6A and 1A6C configurations. The second is more efficient than the first. The main mechanisms involved in the remediation of the soil are dragging by electro-osmotic flux and volatilization. Compared to the reference experiment, $1 \mathrm{C} 6 \mathrm{~A}$ improves removal by $18.5 \%$ versus the $12.9 \%$ improvement obtained in the $1 \mathrm{~A} 6 \mathrm{C}$ test, by electrokinetic transport mechanisms, after a 35-day-long treatment. However, the pesticide volatilization is favored in EKSF with 1A6C (29.9\%) versus 1C6A configuration (14.9\%). 
- Comparing results with those obtained in the remediation of 2,4-D with the same electrode arrangements shows that the differences in the main transport mechanisms can be explained in terms of the very different characteristic of 2,4D and oxyfluorfen.

- Both the 1C6A and the 1A6C configurations may attain good control of the acidic and basic fronts and prevent the acidification or basification of soil. Hence, the negative consequences that can be associated with this undesired process can be avoided in full-scale applications.

\section{Acknowledgements}

The authors acknowledge funding support from the EU and Spanish Government through the MINECO Project CTM2013-45612-R and INNOCAMPUS and CYTEMA E2TP Programs of the University of Castilla La Mancha.

\section{References}

Adams CD, Cozzens RA, Kim BJ. Effects of ozonation on the biodegradability of substituted phenols. Water Research 1997; 31: 2655-2663.

Alcantara MT, Gomez J, Pazos M, Sanroman MA. Electrokinetic remediation of PAH mixtures from kaolin. Journal of Hazardous Materials 2010; 179: 1156-1160.

Alcantara MT, Gomez J, Pazos M, Sanroman MA. Electrokinetic remediation of lead and phenanthrene polluted soils. Geoderma 2012; 173: 128-133.

Alister CA, Gomez PA, Rojas S, Kogan M. Pendimethalin and oxyfluorfen degradation under two irrigation conditions over four years application. Journal of Environmental Science and Health Part B-Pesticides Food Contaminants and Agricultural Wastes 2009; 44: 337-343.

Almeira J, Peng C, Wang Z. Effect of different electrode configurations on the migration of copper ions during the electrokinetic remediation process. Asia-Pacific Journal of Chemical Engineering 2009; 4: 581-585.

Alshawabkeh AN, Gale RJ, Ozsu-Acar E, Bricka RM. Optimization of 2-D electrode configuration for electrokinetic remediation. Journal of Soil Contamination 1999a; 8: 617-635.

Alshawabkeh AN, Yeung AT, Bricka MR. Practical aspects of in-situ electrokinetic extraction. Journal of Environmental Engineering-Asce 1999b; 125: 27-35. 
Cameselle C, Reddy KR. Effects of Periodic Electric Potential and Electrolyte Recirculation on Electrochemical Remediation of Contaminant Mixtures in Clayey Soils. Water Air and Soil Pollution 2013; 224.

Das AC, Debnath A, Mukherjee D. Effect of the herbicides oxadiazon and oxyfluorfen on phosphates solubilizing microorganisms and their persistence in rice fields. Chemosphere 2003; 53: 217-221.

Hahladakis JN, Calmano W, Gidarakos E. Use and comparison of the non-ionic surfactants Poloxamer 407 and Nonidet P40 with HP-beta-CD cyclodextrin, for the enhanced electroremediation of real contaminated sediments from PAHs. Separation and Purification Technology 2013; 113: 104-113.

Hahladakis JN, Lekkas N, Smponias A, Gidarakos E. Sequential application of chelating agents and innovative surfactants for the enhanced electroremediation of real sediments from toxic metals and PAHs. Chemosphere 2014; 105: 44-52.

Jeon E-K, Jung J-M, Kim W-S, Ko S-H, Baek K. In situ electrokinetic remediation of As-, CU-, and $\mathrm{Pb}$-contaminated paddy soil using hexagonal electrode configuration: a full scale study. Environmental Science and Pollution Research 2015; 22: 711-720.

Kim D-H, Jo S-U, Choi J-H, Yang J-S, Baek K. Hexagonal two dimensional electrokinetic systems for restoration of saline agricultural lands: A pilot study. Chemical Engineering Journal 2012; 198: 110-121.

Kim K-Y, Yang W, Logan BE. Impact of electrode configurations on retention time and domestic wastewater treatment efficiency using microbial fuel cells. Water Research 2015; 80: 41-46.

Lima AT, Kleingeld PJ, Heister K, Loch JPG. Removal of PAHs from contaminated clayey soil by means of electro-osmosis. Separation and Purification Technology 2011; 79: 221-229.

Lopez-Vizcaino R, Alonso J, Canizares P, Leon MJ, Navarro V, Rodrigo MA, et al. Electroremediation of a natural soil polluted with phenanthrene in a pilot plant. Journal of Hazardous Materials 2014a; 265: 142-150.

Lopez-Vizcaino R, Alonso J, Canizares P, Leon MJ, Navarro V, Rodrigo MA, et al. Removal of phenanthrene from synthetic kaolin soils by electrokinetic soil flushing. Separation and Purification Technology 2014b; 132: 33-40.

Lopez-Vizcaino R, Saez C, Mena E, Villasenor J, Canizares P, Rodrigo MA. Electro-osmotic fluxes in multi-well electro-remediation processes. Journal of Environmental Science and Health Part a-Toxic/hazardous Substances \& Environmental Engineering 2011; 46: 1549-1557.

Lu X, Yuang S. Electrokinetic removal of chlorinated organic compounds. In: Reddy KR, Cameselle C, editors. Electrochemical Remediation Technologies for Polluted Soils, Sediments and Groundwater. C. John Wiley \& Sons Inc., Hoboken, 2009, pp. 223-227.

Mantzos N, Karakitsou A, Hela D, Patakioutas G, Leneti E, Konstantinou I. Persistence of oxyfluorfen in soil, runoff water, sediment and plants of a sunflower cultivation. Science of the Total Environment 2014; 472: 767-777.

Pazos M, Rosales E, Alcantara T, Gomez J, Sanroman MA. Decontamination of soils containing PAHs by electroremediation: A review. Journal of Hazardous Materials 2010; 177: 1-11.

Peng C, Almeira JO, Gu Q. Effect of electrode configuration on $\mathrm{pH}$ distribution and heavy metal ions migration during soil electrokinetic remediation. Environmental Earth Sciences 2013; 69: 257-265.

Reddy KR, Darko-Kagya K, Al-Hamdan AZ. Electrokinetic Remediation of Pentachlorophenol Contaminated Clay Soil. Water Air and Soil Pollution 2011; 221: 35-44.

Reddy KR, Maturi K, Cameselle C. Sequential Electrokinetic Remediation of Mixed Contaminants in Low Permeability Soils. Journal of Environmental Engineering-Asce 2009; 135: 989-998. 
Ribeiro AB, Mateus EP, Rodriguez-Maroto J-M. Removal of organic contaminants from soils by an electrokinetic process: The case of molinate and bentazone. Experimental and modeling. Separation and Purification Technology 2011; 79: 193-203.

Ribeiro AB, Rodriguez-Maroto JM, Mateus EP, Gomes $\mathrm{H}$. Removal of organic contaminants from soils by an electrokinetic process: the case of atrazine. Experimental and modeling. Chemosphere 2005; 59: 1229-1239.

Risco C, López-Vizcaíno R, Sáez C, Yustres A, Cañizares P, Navarro V, et al. Remediation of soils polluted with 2,4-D by electrokinetic soil flushing with facing rows of electrodes: $A$ case study in a pilot plant. Chemical Engineering Journal 2016a; 285: 128-136.

Risco C, Rodrigo S, Lopez-Vizcaino R, Saez C, Canizares P, Navarro V, et al. Electrokinetic flushing with surrounding electrode arrangements for the remediation of soils that are polluted with 2,4-D: A case study in a pilot plant. Science of the Total Environment 2016b; 545: 256-265.

Risco C, Rodrigo S, López-Vizcaíno R, Sáez C, Cañizares P, Navarro V, et al. Electrokinetic flushing with surrounding electrode arrangements for the remediation of soils that are polluted with 2,4-D: A case study in a pilot plant. Science of The Total Environment 2016c; 545-546: 256-265.

Risco C, Rodrigo S, López-Vizcaíno R, Yustres A, Sáez C, Cañizares P, et al. Electrochemically assisted fences for the electroremediation of soils polluted with 2,4-D: A case study in a pilot plant. Separation and Purification Technology 2015; 156, Part 2: 234-241.

Rodrigo MA, Mena E, Ruiz C, Risco C, Jose Villasenor J, Saez C, et al. Combined Electrokinetic Soil Flushing and Bioremediation for the Treatment of Spiked Soils Polluted with Organics. In: Palmas S, Mascia M, Vacca A, editors. 10th Esee: European Symposium on Electrochemical Engineering. 41, 2014a, pp. 109-114.

Rodrigo MA, Oturan N, Oturan MA. Electrochemically Assisted Remediation of Pesticides in Soils and Water: A Review. Chemical Reviews 2014b; 114: 8720-8745.

Sondhia S. Persistence and bioaccumulation of oxyfluorfen residues in onion. Environmental Monitoring and Assessment 2010; 162: 163-168.

Sondhia S, Dixit A. Persistence of oxyfluorfen residues in the soil of paddy field and detection of its residues in crop produce. Indian Journal of Agricultural Sciences 2010; 80: 926929.

Weng C. Coupled electrokinetics-permeable reactive barriers. In: Reddy KR, Cameselle C, editors. Electrochemical Remediation Technologies for Polluted Soils, Sediments and Groundwater. John Wiley \& Sons, Inc. , Hoboken, New Jersey, 2009, pp. 483-503. 